\title{
G. H. VON WRIGHT Y LA LÓGICA SIN VERDAD*
}

\author{
Daniel González Lagier \\ Universidad de Alicante \\ Pablo E. Navarro \\ CONICET, Argentina
}

RESUMEN. En este breve texto se describe el contexto en el que von WRIGHT escribió el artículo « ¿Lógica sin verdad?» y algunas de las circunstancias de la versión que a continuación se publica.

Palabras clave: G. H. vON WRIGHT, lógica, verdad.

\section{G. H. von WriGht and the Logic Without Truth}

ABSTRACT. This text is an introduction to the context in which Von Wright wrote his «Logic withoout Truth?» and some of the circumstances of the version to be found here below.

Keywords: G. H. von WRIGHT, Logic, Truth.

\footnotetext{
* Fecha de recepción: 19 de abril de 2016. Fecha de aceptación: 1 de septiembre de 2016.
} 

fue la fundamentación de una genuina lógica de norma. El valor específico de esta lógica, en su opinión, se deriva de la especificidad de ciertas verdades lógicas que son peculiares a los conceptos deónticos ${ }^{1}$. Sin embargo, la misma idea de «verdad lógica» en el campo de las normas prescriptivas es compleja ya que ellas no son verdaderas o falsas. En este sentido, una de las ideas más ambiciosas de VON WRIGHT fue reivindicar que «la lógica [...] tiene una alcance más amplio que la verdad $\gg^{2}$. Ahora bien, los sucesivos vaivenes tanto en la historia de la lógica deóntica como en la evolución del pensamiento de VON WRIGHT (i. e., una persistente oscilación entre optimismo y pesimismo filosófico) prueban la dificultad de articular y justificar adecuadamente esta intuición.

A principios de la década de los ochenta, luego de un periodo escéptico, vON WRIGHT creía haber alcanzado una idea definitiva sobre la naturaleza de la lógica deóntica y esperaba ofrecer una justificación aceptable de la naturaleza lógica de los principios específicos del discurso deóntico ${ }^{3}$. Su intuición principal era que la noción de consecuencia lógica se tenía que analizar en conexión con otras ideas, en especial con la noción de racionalidad ${ }^{4}$. $\mathrm{Al}$ respecto, en 1983 reconoce que, en un sentido importante, tenían razón quienes negaban que hubiese una genuina lógica de normas, aunque al mismo tiempo, subraya ${ }^{5}$ :

Pero la actividad de dictar normas, y también las normas mismas, pueden ser juzgadas bajo diversos aspectos y estándares de racionalidad. Más aún, algunos de estos aspectos pueden ser asociados con consideraciones de una naturaleza estrictamente lógica...

En 1985 VON WRIGHT señala que su posición tiene algo en común con el escepticismo de HäGERSTRÖM y (el último) $\operatorname{KELSEN}^{6}$, pero añade ${ }^{7}$ :

La lógica deóntica, podría decirse, no es una lógica de normas ni una lógica de proposiciones normativas sino un estudio de las condiciones que deben satisfacerse en una actividad racional de dictar normas. Es estrictamente una lógica porque las condiciones que establece se derivan de las relaciones lógicas entre estados de cosas en los mundos ideales previstos en los códigos normativos.

1 G. H. von Wright, «Deontic Logic», en Logical Studies, 63 (London: Routledge \& Kegan Paul, 1963).

2 G. H. vON Wright, «Preface», en Logical Studies, op. cit., vii.

3 G. H. VON WRIGHT, «Norms, Truth and Logic» en Practical Reason, 130-209 (Oxford: Blackwell, 1983). Vid., también, G. H. VON WRIGHT, «Is There a Logic of Norms?», en Ratio Iuris, 4 (1991), 265-283. En este último trabajo se incluye una larga nota inicial de pie de página, donde VON WRIGHT repite que la noción de racionalidad vino en su ayuda para conducirlo a la salida del laberinto escéptico. Este trabajo está reproducido, lamentablemente sin esa nota inicial, en G. H. vON WRIGHT, Six Essays in Philosophical Logic, 35-53 (Helsinki: Acta Philosophica Fennica,1996).

4 G. H. vON WRIGHT, «Is There a Logic of Norms?», en Ratio Iuris, 4 (1991), 265-283.

5 G. H. vON WRIGHT, «Norms, Truth and Logic», en Practical Reason, op. cit., 132.

${ }^{6}$ G. H. von Wright, «A Pilgrim's Progress - Voyage d'un pélerin», en A. Mercier et al. (eds.), Philosophes critiques d'eux-memes, vol. 12, pp. 257-294 (Bern: Verlag Peter Lang, 1985). Reproducido en «A Pilgrim's Progress», en G. H. VON WRIGHT, The Tree of Knowledge and Other Essays, 109 (New York: Brill, 1993). En adelante, se cita conforme a esta última versión inglesa.

7 G. H. vON WRIGHT, «A Pilgrim's Progress», op. cit., 111. 
Pocos años después, Carlos AlChOuRRón y Antonio A. MARTINo publicaban diversas versiones de un importante artículo con el objetivo de defender una «lógica sin verdad» ${ }^{8}$. En este trabajo, ellos defienden una manera abstracta de caracterizar la noción de consecuencia lógica. Esta concepción va más allá de los tradicionales enfoques sintácticos y semánticos y permite elaborar una genuina lógica de normas ya que no descansa sobre la noción de verdad?

Sin duda, el artículo de ALCHOURRÓn y MARTINO sirvió como estímulo para que VON WRIGHT revisase, en general, el análisis de las ideas centrales de la lógica (i. e., la noción de consecuencia, contradicción, etc.) y de la lógica deóntica, en particular. Entre 1988 y 1989 VON WRIGHT terminó una primera versión de un artículo llamado «Logic without Truth?» y aunque no estaba enteramente satisfecho con el resultado, pensaba que el trabajo podía ser enviado a la imprenta. De hecho, en 1990 ya conocía que Antonio A. MARTINO lo traduciría al italiano como «Lógica senza verità?», aunque su publicación se demoró hasta $1996^{10}$.

A pesar del interrogante que enmarca al título de su trabajo, en esa época vON WRIGHT creía firmemente en que la lógica se extendía más allá de la verdad. ¿̇A qué se debe, entonces, ese signo de interrogación en el título? Una posible respuesta es que si bien VON WRIGHT creía que la lógica tenía un alcance más amplio que la verdad, él tenía dudas acerca del modo en que ALCHOURRÓN y MARTINO enfrentaban este desafío. Aunque el trabajo de VON WRIGHT no es una crítica a la propuesta de ALCHOURRÓN y MARTINO, el mismo contiene claramente un análisis alternativo a esa concepción abstracta de la (noción de consecuencia) lógica ${ }^{11}$. Con debidas cautelas, podría decirse que el enfoque defendido por VON WRIGHT es más pragmático que abstracto y, con una cierta dosis de imaginación, se podría añadir que en el trasfondo de la oposición entre los enfoques de ALCHOURRÓN/MARTINO y VON WRIGHT, resuena el eco de las diferentes visiones de dos grandes lógicos y filósofos: FREGE y (el segundo) WitTGENSTEIN.

La posición final de VON WRIGHT puede extraerse del siguiente párrafo de «Logic without Truth?»:

Luego de un largo peregrinaje por las tierras inhóspitas de la lógica deóntica, volví sobre la cuestión en lo que entonces creé que sería mi última contribución a la disciplina, mi ensayo «Normas, verdad y lógica».En ese artículo, al igual que los primeros positivistas, negué que hubiera relaciones lógicas entre las normas porque ellas carecen de valor de verdad. Pero al mismo tiempo traté de mostrar cómo las normas genuinas pueden ostentar lo que podrían llamarse relaciones cuasi-lógicas, no definibles únicamente en términos de

8 Vid. C. AlChOURRón y A. A. MARTINO, «Lógica sin verdad», en Theoria (San Sebastián, 1987-1988). Posteriormente aparecieron una versión en francés (Revue Internationale de Semantique Juridique, III, 1989), en italiano (Sistemi Esperti Giuridici l»Intelligenza Artificiale applicata al Diritto, editado por P. MARIANI y D. TISCORNIA, 1989) y en inglés «Logic without Truth», en Ratio Iuris, 3 (1990), 46-67.

9 Posteriormente, AlCHOURRÓN ofreció un análisis más completo de la misma idea en «Concepciones de la lógica», en C. ALCHOURRÓN et al., Lógica, Enciclopedia Iberoamericana de Filosofía, vol. 7, 11-48 (Madrid: Trotta, 1995).

${ }_{10}$ G. H. vON WRIGHT, «Logica senza verità», en A. A. MARTINo (ed.), Logica, Informatica, Diritto, 38-58 (Pisa: Servizio Editoriale Universitario, 1996).

${ }^{11}$ Para una comparación de la evolución de las ideas de VON WRIGHT y ALCHOURRÓN acerca de la lógica deóntica, vid. E. BulYgin, «G. H. von Wright's and C. E. Alchourrón's Struggle with Deontic Logic», en The Human Condition - Conference In Honour Of Georg Henrik Von Wright's Centennial Anniversary, Universidad de Helsinki, 2016 (en prensa). 
verdad y falsedad sino con la colaboración adicional de la noción de racionalidad. Todavía pienso que este movimiento constituyó una salida correcta del laberinto lógico en el que había estado vagando durante más de tres décadas. Pero ahora estoy dispuesto a conceder que esas relaciones cuasi-lógicas, dependientes de la noción de racionalidad, son genuinas relaciones de consecuencia y contradicción lógica. En consecuencia, he vuelto finalmente a mi opinión primigenia: que «la lógica trasciende la verdad».

Una copia del texto inglés - que como mencionamos anteriormente fue traducido al italiano en 1996 - fue el origen de nuestra traducción al castellano que aquí presentamos (en adelante y por razones de simplicidad, ese texto inglés será denominada como «la versión original»). Sin embargo, gracias a la ayuda de Bernt ÖSTERMAN y Thomas WALLGREN, responsables del Archivo Georg Henrik von Wright, en la Universidad de Helsinki, pudimos acceder a una versión revisada de ese trabajo. Nuestra tarea editorial se ha limitado a traducir y pulir esta segunda versión, eliminando del texto aquellas partes que VON WRIGHT había decidido suprimir.

Respecto de la versión original se aprecian dos importantes modificaciones. Por una parte, las primeras secciones han sido escritas y organizadas de manera diferente $\mathrm{y}$, en segundo lugar, hay un intento de independizar este artículo del trabajo de AlCHOURRÓN y MARTINO. Dos ejemplos pueden servir para ilustrar esta impresión.

1. En la p. 4 de la versión original, VON WRIGHT señala:

Tengo pocas razones para criticar lo que ellos dicen. Pero no pienso que se sea suficiente caracterizar una noción de consecuencia lógica en la manera puramente abstracta que los autores favorecen. Porque, me parece, cualquier intento de caracterización debe estar justificado en términos semánticos o aún pragmáticos, de acuerdo con la comprensión intuitiva de los conceptos tal como ellos se dan en el razonamiento efectivo (actual reasoning).

Este párrafo, sin embargo, ha desaparecido en la reformulación de las primeras secciones.

2. Aunque sigue manteniéndose la referencia al artículo de ALCHOURRÓN y MARTINO $^{12}$, hay párrafos tachados a mano con el objeto de evitar una confrontación con ambos autores.

Por ejemplo, en la p. 26 de la versión original dice

Espero que los anteriores ejemplos muestren con suficiente claridad cómo podemos «rescatar» la noción de implicación o consecuencia lógica de las «paradojas» de que una contradicción implica a cualquier proposición y de que cualquier proposición implica a cualquier tautología. La construcción de esta salvaguardia en la noción de implicación es, parecería ser, la única cuestión en la que mi tratamiento de esta muy debatida cuestión difiere de la noción de consecuencia sostenida por los autores del artículo «Lógica sin verdad».

12 En la versión original, ALCHOURRÓN y MARTINO son mencionados cuatro veces en el texto principal, mientras que esas citas se reducen a una única mención en el texto principal de la segunda versión de su ensayo. Por supuesto, esto no significa que VON WRIGHT no valorase ese trabajo, sino más bien es probable que él estuviese convencido de que la dinámica de sus propias ideas exigían un desarrollo independiente de la línea de trabajo de ALCHOURRÓN y MARTINO. 
Este párrafo no ha sido reformulado de modo alguno en la versión revisada.

Sin embargo, parece claro que VON WRIGHT tampoco estaba conforme con esta última revisión ya que en el Archivo von Wright, grapada a la última versión, se encuentra la siguiente anotación hecha en inglés:

Esta es una versión de «Logica senza verità» con algunas mejoras. Al igual que el artículo «Conditionality» puede pensarse como publicable (pero también podría aún ser mejorada).

Marzo de 1990

¿Qué sigue? Me temo que debo regresar otra vez a la lógica deóntica. Normas y conectivas veritativas. Normas y proposiciones normativas. Una lógica deóntica que admita lagunas $-y$ otra que admita «contradicciones»-en el derecho.

¿Otra vez la implicación (entailment)? Me parece que en las dos últimas secciones del (presente) artículo «Logic without Truth?» be logrado aclarar mi posición en relación con mi trabajo sobre implicación del año 1957. ¿Podría escribir un nuevo trabajo corto sobre implicación?

En una perspectiva más amplia también aparece el problema del significado veritativo (truth- meaning problem). ¿Qué es comprender el significado de un enunciado y declarar que una proposición es verdadera? Aqui, la aceptación y el rechazo al igual que otras nociones relacionadas adquieren importancia.

8 de Marzo. 1990

Al igual que el resto de la obra de VON WRIGHT, «Logic without Truth?» es un trabajo filosóficamente profundo; rico en ideas y simple en su aparato formal. Sin duda alguna, su lectura permite obtener una visión compacta de muchos de los problemas que marcaron el desarrollo de la lógica deóntica en el siglo XX.

Finalmente, deseamos agradecer a Bernt Österman, Thomas WALLgren (WWA Archives), y Eugenio BULYGIN por su ayuda para obtener los permisos correspondientes para traducir este trabajo. La autorización para su publicación fue amablemente proporcionada por Benedict VON WRIGHT y Anita VON WRIGHT. 